Pacific Journal of Mathematics

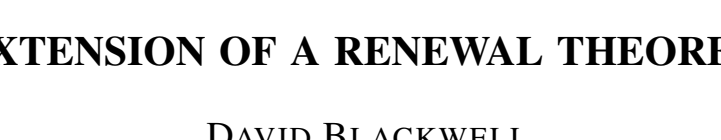




\title{
EXTENSION OF A RENEWAL THEOREM
}

\author{
DAVID BLACKWELL
}

1. Introduction. A chance variable $x$ will be called a d-lattice variable if

$$
\sum_{n=-\infty}^{\infty} \operatorname{Pr}\{x=n d\}=1
$$

and

$d$ is the largest number for which (1) holds.

If $x$ is not a $d$-lattice variable for any $d, x$ will be called a nonlattice variable. The main purpose of this paper is to give a proof of:

THEOREM 1. Let $x_{1}, x_{2}, \cdots$ be independent identically distributed chance variables with $E\left(x_{1}\right)=m>0$ (the case $m=+\infty$ is not excluded); let $S_{n}=$ $x_{1}+\cdots+x_{n}$; and, for any $h>0$, let $U(a, h)$ be the expected number of integers $n \geq 0$ for which $a \leq S_{n}<a+h$. If the $x_{n}$ are nonlattice variables, then

$$
U(a, h) \rightarrow \frac{h}{m}, 0
$$

as $a \longrightarrow+\infty,-\infty$.

If the $x_{n}$ are d-lattice variables, then

$$
U(a, d) \rightarrow \frac{d}{m}, 0
$$

as $a \longrightarrow+\infty,-\infty$.

(If $m=+\infty, h / m$ and $d / m$ are interpreted as zero. )

This theorem has been proved (A) for nonnegative $d$-lattice variables by Kolmogorov [5] and by Erdös, Feller, and Pollard [4]; (B) for nonnegative nonlattice variables by the writer [1], using the methods of [4]; (C) for $d$-lattice variables by Chung and Wolfowitz [3]; (D) for nonlattice variables such that the distribution of some $S_{n}$ has an absolutely continuous part and $m<\infty$ by Chung

Received June 28, 1952. This paper was written under an Office of Naval Research contract.

Pacific J. Math. 3 (1953), $315-320$ 
and Pollard [2], using a purely analytical method; and (E) in the form given here by Harris (unpublished). Harris' proof does not essentially use the results of the special cases (A), (B), (C), (D); the proof given here obtains Theorem 1 almost directly from the special cases (A) and (B) by way of an integral identity and an equation of Wald.

2. An integral identity. Let $N_{1}$ be the smallest $n$ for which $S_{n}>0$, and write $z_{1}=S_{N_{1}}$; let $N_{2}$ be the smallest $n>0$, for which $S_{N_{1}+n}-S_{N_{1}}>0$, and write $z_{2}=S_{N_{1}}+N_{2}-S_{N_{1}}$, and so on. Continuing in this way, we obtain sequences $N_{1}$, $N_{2}, \cdots ; z_{1}, z_{2}, \cdots$ of independent, positive, identically distributed chance variables such that

$$
S_{N_{1}}+\cdots+N_{K}=z_{1}+\cdots+z_{K}
$$

Let $V(t), R(t)$ denote the expected number of integers $n \geq 0$ for which

$$
T_{n}=z_{1}+\cdots+z_{n} \leq t \text { and }-t \leq S_{n} \leq 0,
$$

$n<N_{1}$, respectively. That $V(t)<\infty$ follows from a theorem of Stein [6], and that $R(t)<\infty$ follows from $E\left(N_{1}\right)<\infty$, which we show in the next section. The integral identity is:

THeоrem 2: $U(a, h)=\int_{0}^{\infty}[R(t-a)-R(t-a-h)] d V(t)$.

Proof. If $n_{K}$ is the number of integers $n$ with

$$
N_{1}+\cdots+N_{K} \leq n<N_{1}+\cdots+N_{K+1} \text { and } a \leq S_{n}<a+h,
$$

we have

$$
E\left(n_{K} \mid T_{K}=t\right)=R(t-a)-R(t-a-h),
$$

so that

$$
E\left(n_{K}\right)=\int_{0}^{\infty}[R(t-a)-R(t-a-h)] d F_{K}(t),
$$

where $F_{K}(t)=\operatorname{Pr}\left\{T_{K} \leq t\right\}$. Summing over $K=0,1,2, \cdots$, and using the fact that

$$
V(t)=\sum_{K=0}^{\infty} F_{K}(t),
$$


we obtain the theorem.

3. Wald's equation. The main purpose of this section is to note that $E\left(N_{1}\right)$ is finite, so that an equation of Wald [ 7, p. 142] holds.

THEOREM 3. $E\left(N_{1}\right)<\infty$ and $m E\left(N_{1}\right)=E\left(z_{1}\right)$, so that $m, E\left(z_{1}\right)$ are both finite or both infinite.

Proof. In showing $E\left(N_{1}\right)$ finite, we may suppose $\left\{x_{n}\right\}$ bounded above; for defining $x_{n}^{*}=\min \left\{s_{n}, M\right\}$ yields an $N_{1}^{*} \geq N_{1}$; choosing $M$ sufficiently large makes $E\left(x_{n}^{*}\right)>0$, and $E\left(N_{1}^{*}\right)<\infty$ implies $E\left(N_{1}\right)<\infty$. Since

$$
\frac{T_{K}}{K}=\frac{S_{N_{1}+\cdots+N_{K}}}{N_{1}+\cdots+N_{K}} \cdot \frac{N_{1}+\cdots+N_{K}}{K} \text {, }
$$

we obtain, letting $K \longrightarrow \propto$ and using the strong law of large numbers, first that $E\left(z_{1}\right)=m E\left(N_{1}\right)$ and next since if $\left\{x_{n}\right\}$ is bounded above and $\left\{z_{n}\right\}$ is bounded, that $E\left(N_{1}\right)$ is finite in this case and consequently in general.

4. The d-lattice case. For $d$-lattice variables, Theorem 2 yields

$$
U(n d, d)=\sum_{s=0}^{\infty} r(s-n) v(s)=\sum_{s=0}^{\infty} r(s) v(s+n),
$$

where $r(s)=R(s d)-R([s-1] d)$ and $v(s)=V(s d)-V([s-1] d)$. Now

$$
\sum_{s=0}^{\infty} r(s)=\lim _{t \rightarrow \infty} R(t)=E\left(N_{1}\right)<\infty
$$

Theorem (A) asserts that

$$
v(n) \rightarrow \frac{d}{E\left(z_{1}\right)}, 0
$$

applying this to (1) yields

$$
U(n d, d) \rightarrow \frac{d E\left(N_{1}\right)}{E\left(z_{1}\right)}, 0
$$

and Wald's equation yields Theorem 1 for $d$-lattice variables.

5. The nonlattice case. For nonlattice variables we have, rewriting Theorem 
2 with a change of variable,

$$
U(a, h)=\int_{M}^{\infty}[R(t)-R(t-h)] d V(t+a) .
$$

For any $M>0$, write

$$
U(a, h)=I_{1}(M, a, h)+I_{2}(M, a, h),
$$

where

$$
I_{1}=\int_{0}^{M}[R(t)-R(t-h)] d V(t+a)
$$

and

$$
I_{2}=\int_{0}^{\infty}[R(t)-R(t-h)] d V(t+a) .
$$

Theorem B applied to $\left\{z_{n}\right\}$ yields

$$
V(t+h)-V(t) \rightarrow \frac{h}{E\left(z_{1}\right)}
$$

for all $h>0$ as $t \rightarrow \infty$, so that, since $R(t)$ is monotone,

$$
\begin{aligned}
I_{1} & =\int_{0}^{M} R(t) d V(t+a)-\int_{0}^{M-h} R(t) d V(t+a+h) & \\
& \rightarrow \frac{1}{E\left(z_{1}\right)} \cdot \int_{M-h}^{M} R(t) d t, 0 & \text { as } a \rightarrow \infty,-\infty
\end{aligned}
$$

for fixed $M, h$. We now show that, for fixed $h, I_{2}(M, a, h) \rightarrow 0$ as $M \rightarrow \infty$ uniformly in $a$. We have

$$
\begin{aligned}
I_{2} & =\sum_{n=0}^{\infty} \int_{M+n h}^{M+(n+1) h}[R(t)-R(t-h)] d V(t+a) \\
& \leq \sum_{n=0}^{\infty} R_{1}(M, n)[V(a+M+(n+1) h)-V(a+M+n h)],
\end{aligned}
$$

where

$$
R_{1}(M, n)=\sup [R(t)-R(t-h)]
$$


as $t$ varies over the interval $(M+n h, M+(n+1) h)$. Since, by Theorem (B),

$$
V(b+h)-V(b) \rightarrow \frac{h}{E\left(z_{1}\right)}
$$

there is a constant $c$ (for the given $h$ ) such that

$$
I_{2}(M, a, h) \leq c \sum_{n=0}^{\infty} R_{1}(M, n)
$$

for all $M$ and $a$.

Now

$\sum_{n=0}^{\infty} R_{1}(M, 2 n) \leq E\left(N_{1}\right)-R(M)$ and $\sum_{n=0}^{\infty} R_{1}(M, 2 n+1) \leq E\left(N_{1}\right)-R(M)$, and $R(M) \rightarrow E\left(N_{1}\right)$ as $M \longrightarrow \infty$. Thus

$$
\left|U(a, h)-I_{1}(M, a, h)\right|<\epsilon(M, h)
$$

for all $a$, where $\in(M, h) \longrightarrow 0$ as $H \longrightarrow \infty$ for fixed $h$. Then

$$
\begin{aligned}
\mid U\left(a, h-\frac{h E\left(N_{1}\right)}{E\left(z_{1}\right)} \mid \leq \epsilon(m, h)\right. & +\left|I_{1}(M, a, h)-\frac{1}{E\left(z_{1}\right)} \int_{M-h}^{M} R(t) d t\right| \\
& +\left|\frac{1}{E\left(z_{1}\right)} \int_{M-h}^{M} R(t) d t-h E\left(N_{1}\right)\right|,
\end{aligned}
$$

so that

$$
\begin{aligned}
& \limsup _{a \rightarrow \infty}\left|U(a, h)-\frac{h E\left(N_{1}\right)}{E\left(z_{1}\right)}\right| \\
& \leq \in(M, h)+\frac{1}{E\left(z_{1}\right)}\left|\int_{M-h}^{M} R(t) d t-h E\left(N_{1}\right)\right| .
\end{aligned}
$$

Letting $M \longrightarrow \infty$ yields

$$
U(a, h) \rightarrow \frac{h E\left(N_{1}\right)}{E\left(z_{1}\right)}
$$

and Wald's equation yields Theorem 1 for $a \longrightarrow \infty$. Similarly, 


$$
U(a, h) \leq \epsilon(M, h)+\left|I_{1}(M, a, h)\right|
$$

for all $a$, so that

$$
\lim _{a \rightarrow-\infty} \sup _{a \rightarrow} U(a, h) \leq \epsilon(M, h)
$$

and $U(a, h) \longrightarrow 0$ as $a \longrightarrow-\infty$. This completes the proof.

\section{REFERENCES}

1. D. Blackwell, A renewal theorem, Duke Math. J. 15 (1948), 145-151.

2. K. L. Chung and Harry Pollard, An extension of renewal theory, Proc. Amer. Math. Soc. 3 (1952), 303-309.

3. K. L. Chung and J. Wolfowitz, On a limit theorem in renewal theory, Ann. of Math. 55 (1952), 1-6.

4. P. Erdös, W. Feller, and H. Pollard, A theorem on power series, Bull. Amer. Math. Soc. 55 (1949), 201-204.

5. A. Kolmogorov, Anfangsgründe der Theorie der Markoffschen Ketten mit unendlich vielen möglichen Zuständen, Mat. Sbornik N.S. 1 (1936), 607-610.

6. C. Stein, A note on cumulative sums, Ann. Math. Statistics 17 (1946), 498-499.

7. A. Wald, Sequential tests of statistical hypotheses, Ann. Math. Statistics 16 (1945) 117-186.

Stanford UNIVERSITY 


\section{PACIFIC JOURNAL OF MATHEMATICS}

\section{EDITORS}

\section{R. U. FOEINSON}

University of California

Berkeley 4, California

E. HewitT

University of Washington

Seattle 5 , Washington
P. P. DILWOR TH

California Institute of Technology

Pasadena 4, California

E. F. BECKENBACH

University of California

Los Angeles 24, California

\section{ASSOCIATE EDITORS}

$\begin{array}{llll}\text { H. BUSEMANN } & \text { P. R. HALMOS } & \text { BØRGE JESSEN } & \text { J. J. STOKER } \\ \text { HERBERT FFDERER } & \text { IIEINZ HOPF } & \text { PAUL LÉVY } & \text { E. G. STRAUS } \\ \text { MARSHALL, IIALI } & \text { R. D. JAMES } & \text { GEORGE PÓLYA } & \text { KÖSAKU YOSIDA }\end{array}$

\section{SPONSORS}

UNIVERSITY OF BRITISH COLUMBIA

CALIFORNIA INSTITUTE OF TECHNOLOGY.

UNIVERSITY OF CAIJIFORNIA, BERKELEY

UNIVERSITY OF CAIJIFORNIA, DAVIS

UNIVERSITY OF CALIFORNIA, LOS ANGELES

UNIVERSITY OF CALIFORNI A, SANTA BARBARA

UNIVERSITY OF NEVADA

OREGON STATE COLLEGE

UNIVERSITY OF OREGON

\author{
UNIVERSITY OF SOU TIERN CALIFORNIA \\ STANFORD RESEARCH INSTITUTE \\ STANFORD UNIVERSITY \\ WASHINGTON STATE COLLEGE \\ UNIVERSITY OF WASHINGTON \\ AMERICAN MATHEMATICAL SOCIETY \\ NATIONAL BUREAU OF STANDARDS, \\ INSTITUTE FOR NUMERICAL ANALYSIS
}

Mathematical papers intended for publication in the Pacific Journal of Mathematics should be typewritten (double spaced), and the author should keep a complete copy. Manuscripts may be sent to any of the editors except Robinson, whose term expires with the completion of the present volume; they might also be sent to M.M. Schiffer, Stanford University, Stanford, California, who is succeeding Robinson. All other communications to the editors should be addressed to the managing editor, E. F. Beckenbach, at the address given above.

Authors are entitled to receive 100 free reprints of their published papers and may obtain additional copies at cost.

The Pacific Journal of Mathematics is published quarterly, in March, June, September, and December. The price per volume (4 numbers) is $\$ 8.00$; single issues, $\$ 2.50$. Special price to individual faculty members of supporting institutions and to individual members of the American Mathematical Society: $\$ 4.00$ per volume; single issues, $\$ 1.25$.

Subscriptions, orders for back numbers, and changes of address should be sent to the publishers, University of California Press, Berkeley 4, California.

Printed at Ann Arbor, Michigan. Entered as second class matter at the Post Office, Berkeley, California.

\section{UNIVERSITY OF CALIFORNIA PRESS • BERKELEY AND LOS ANGELES}




\section{Pacific Journal of Mathematics}

\section{Vol. 3, No. 2 \\ April, 1953}

William George Bade, An operational calculus for operators with spectrum

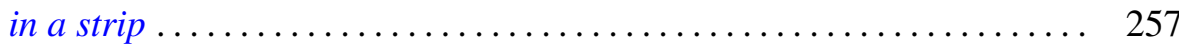

E. F. Beckenbach and Lloyd Kenneth Jackson, Subfunctions of several variables ..................................... 291

David Blackwell, Extension of a renewal theorem ................. 315

L. Carlitz, Some theorems on the Schur derivative ................ 321

Paul Arnold Clement, Generalized convexity and surfaces of negative curvature..................................... 333

Merrill M. Flood, On the Hitchcock distribution problem ............... 369

Watson Bryan Fulks, On the unique determination of solutions of the heat

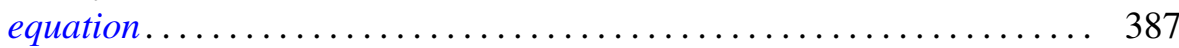

John W. Green, Length and area of a convex curve under affine transformation .................................... 393

William Gustin, An isoperimetric minimax .................. 403

Arthur Eugene Livingston, Some Hausdorff means which exhibit the Gibbs'

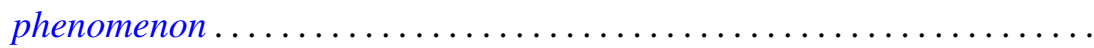

Charles Loewner, On generation of solutions of the biharmonic equation in the plane by conformal mappings ..................... 417

Gábor Szegő, Remark on the preceding paper of Charles Loewner ....... 437

Imanuel Marx and G. Piranian, Lipschitz functions of continuous

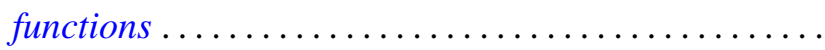

Ting-Kwan Pan, The spherical curvature of a hypersurface in Euclidean space ..

Ruth Lind Potter, On self-adjoint differential equations of second order ...

E. H. Rothe, A note on the Banach spaces of Calkin and Morrey...

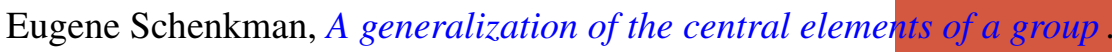

A. Seidenberg, A note on the dimension theory of rings .. . . 